\title{
Huntington's disease and leprosy in a New Guinea Highlander
}

\section{EUAN M SCRIMGEOUR}

From the University Department of Medicine, Goroka Base Hospital, Goroka, Papua New Guinea.

SUMMARY Huntington's disease (HD) was observed in a 45-year-old male Melanesian patient from the Eastern Highlands Province of Papua New Guinea. The patient had multiple peripheral $\tilde{N}^{\circ}$ nerve palsies as a result of tuberculoid leprosy and had been resident in the leprosy ward of Goroka $\sigma^{\circ}$ Base Hospital for over 6 years. During this time his HD had remained undiagnosed. This is the first report of HD in the Highlands of New Guinea.

Huntington's disease in the adult usually presents with the onset of grimacing and choreoathetosis in early to middle life accompanied by progressive dementia. The condition is transmitted as an autosomal dominant trait with full penetrance. HD has previously been described in Melanesians in the Solomon Islands, ${ }^{1}$ New Britain, ${ }^{2}$ and Papua, ${ }^{3}$ but

Received for publication 16 February 1983. Accepted for publication 5 April 1983. this is the first report of the disease in the Highlands of New Guinea.

\section{Family studies}

All members of the families studied were Melanesia and belonged to the Yagaria linguistic group of the Lufa District of the Eastern Highland Province of Papua New Guinea (fig 1). Their pedigree, depicted

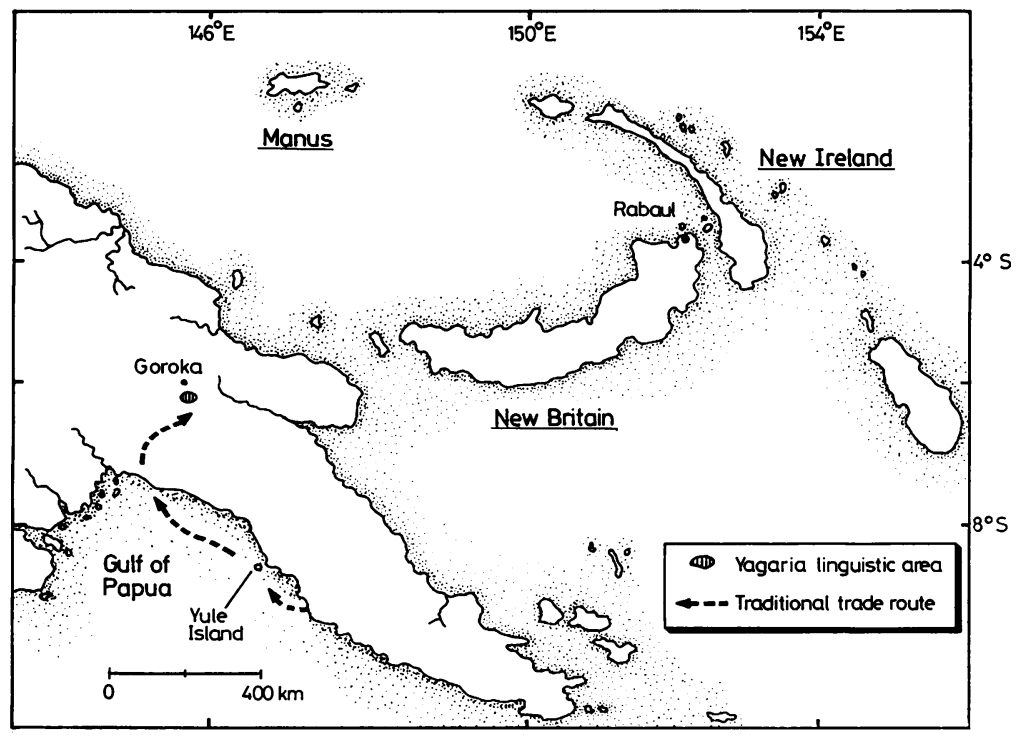

FIG 1 Location of the Yagaria linguistic area near Goroka in the Eastern Highlands Province of Papua New Guinea. Traditional trade routes are indicated by arrowed lines. 


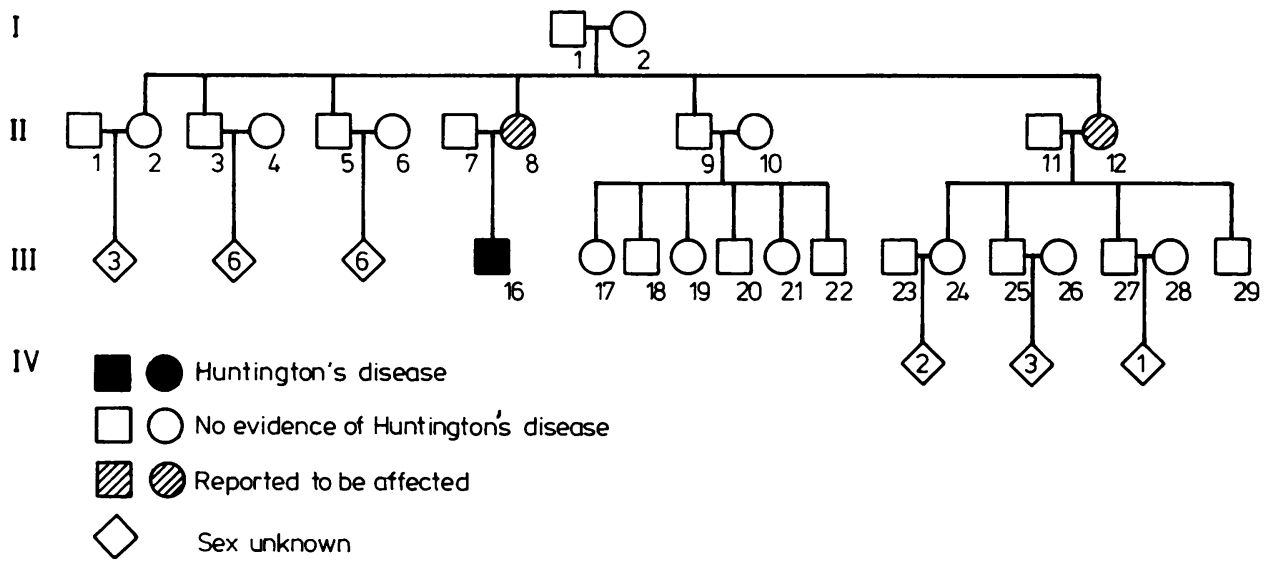

FIG 2 Family pedigree.

in fig 2, shows that all subjects belonged to one kindred. Autosomal dominant inheritance is indicated.

\section{Case report}

Subject III.16 was an unmarried Melanesian male aged about 45 years. In the late 1960s he was diagnosed as having tuberculoid leprosy and was started on dapsone. No medical records of this period have survived although a paramedical worker, an aid post orderly who knew him then, reported that there was no evidence of involuntary movements or grimacing at that time. In 1965 he moved to Mount Hagen to be under medical supervision because of peripheral nerve damage and in 1975 he was transferred to the leprosy unit in Goroka Base Hospital. Since that time he has remained almost continuously an in-patient in the hospital, being severely incapacitated by his nerve lesions.

On examination he had marked grimacing (fig 3). There was impairment of vertical conjugate gaze and rapid eye movements. He was unable to keep his tongue extruded and mimicral apraxia was noted. Speech was halting, explosive, and difficult to comprehend because of variable dysphonia. Frequent irregular choreiform movements of his head, shoulders, and limbs were apparent. On the right, he had a severe claw hand deformity with phalangeal resorption and trophic ulcers, and triple nerve lesions of the left hand had resulted in a drop wrist and flail hand. Both hands were anaesthetic. Marked thickening of all major peripheral nerves in the upper limb, especially the right ulnar nerve, was present. No voluntary or involuntary movement was

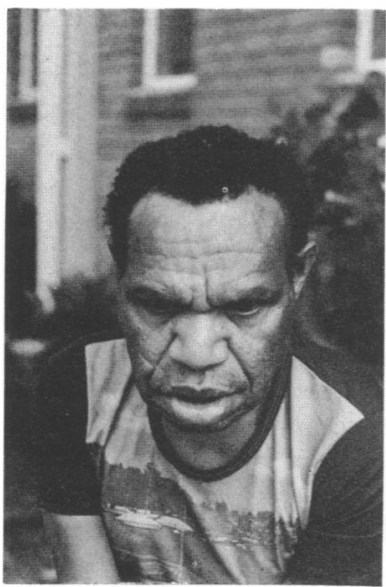

FIG 3 Patient grimacing.

evident in the hands or digits except for wrist movements on the right. Despite these severe disabilities he had been taught by a therapist in previous years to knit, and he passed the time in this occupation, despite frequent interruptions by involuntary movements.

In the lower limbs he had multiple peripheral nerve palsies. Bilateral drop foot had been treated previously by tendon transfer operations which had been most successful on the right. He had anaesthetic feet with trophic ulcers on the heels and extensive bone resorption had occurred. He walked with crutches and supported his weight on the right foot as there was residual foot drop on the left. Choreiform movements superimposed on these disabilities resulted in an irregular ataxic gait. 
Because of his dysarthria it was difficult to assess his mental function; however, impaired memory for distant and recent events could be detected. Those who could converse with him in his own language claimed that his remarks were childish. Despite having been abandoned by his family and being confined to hospital, he was unfailingly and perhaps inappropriately cheerful. His standards of behaviour and personal care were good and, as noted, he kept himself busy knitting. It was concluded that he had mild dementia. There was no evidence of other neurological deficits and pyramidal tract and cerebellar functions were normal.

\section{Family cases}

Subject II.8, the mother of subject III.16, was reported to have been well until 1963 when she developed the gradual onset of grimacing, incoordination of the limbs, ataxia, and dysarthria. She was said to have become demented and spent the last 3 months of her life lying helpless and incontinent on the floor of her hut. She died in 1968 aged about 50 years. Relatives reported that her illness resembled that of subject III.16.

Subject II.7 was reported to have been normal until in early adult life he died from acute gastroenteritis.

Subject II.12 was said to have been well until about 1960 when she developed grimacing, peculiar involuntary movements, and ataxia. Ultimately she became incontinent, demented, and bedridden, dying in 1967 aged about 45 years. The relatives state her illness was closely similar to that exhibited by subjects II.8 and III.16.

Subject I.I died in middle age from a spear wound sustained in tribal warfare and his wife, subject I.2, was reported to have died in middle age from sorcery. Neither was known to have had neurological or psychiatric illness before death.

\section{Discussion}

The diagnosis of Huntington's disease in this family is supported by the presentation of chronic chorea with onset in middle adult life, accompanied by dementia and with evidence of autosomal dominant inheritance. There was no evidence to suggest the presence of other causes of chorea, such as Sydenham's chorea in association with rheumatic fever and hepatolenticular dysfunction. In the latter recessively inherited condition, rigidity and tremor are usually noted. Kayser-Fleisher rings resulting from deposition of copper in the cornea may be observed and liver function is disturbed. In the patient studied, liver function studies were $\stackrel{\mathbb{\Phi}}{\mathbb{Q}}$ normal.

Chorea may occur occasionally in presenile $\Rightarrow$ dementia, but in this case a positive family history is $\stackrel{\oplus}{\rightarrow}$ absent. In tardive dyskinesia, which may be associa- $\bar{c}$ ted with chronic phenothiazine or butyrophenone $\frac{\bar{\sigma}}{\bar{x}}$ treatment, although there may be grimacing and $\frac{\bar{\rho}}{\vec{D}}$ involuntary movements, dysarthria and ataxia are $\mathbb{\mathscr { Q }}$ not present. The only medication subject III.16 is known to have taken previously was dapsone. Although 5 years' treatment is standard for this type $?$ of leprosy he had been on dapsone for over a decade. $\vec{\omega}$ However, this drug is not known to cause chorea.

In kuru, which is a fatal subacute cerebellar degeneration caused by an unconventional virus, clinical disease usually lasts from 12 to 18 months, ${ }^{4}$. whereas the mean duration of clinical illness in HD varies from $10 \cdot 5$ to 16 years. ${ }^{56}$ Although ataxia, $\vec{N}$ incoordination, and dysarthria develop, choreiform 0 movements are not usually observed. Grimacing is $?$ not a feature of kuru although facial dystonia may $\vec{\nabla}$ be noted. ${ }^{7}$ In kuru, when dementia occurs, it generally $\mathbb{D}$ becomes apparent in the later stages of the disease, ${ }^{7} \frac{\Phi}{3}$ although early onset of dementia has been reported. ${ }^{8} \frac{\partial}{\sigma}$ In HD, dementia, in particular memory loss, tends $\frac{\mathbb{Q}}{-}$ to become established relatively early in the disease ${ }^{9} \vec{\bullet}$

Kuru was at one time very common in the adjaceg Fore region and cases had also been reported in the Yagaria linguistic area. ${ }^{10}$ Informants were familis with the disease and they reported that the clinical features exhibited by subjects II.8 and II.12 were different from those of kuru.

It is surprising that a diagnosis of HD was not $\stackrel{\mathbb{Q}}{\beth}$ previously made in subject III.16 who had been $\overrightarrow{\overrightarrow{0}}$ under the care of several specialist physicians. Presumably the severity of his leprosy nerve lesions, which had abolished choreiform movements of the digits, and the fact that his gait was difficult to assess because of his partial foot drop and use of crutches, had masked some of the characteristic diagnostic $\frac{5}{3}$ features of HD. It is likely also that his disease was less obvious in earlier years. Yet the aid post $\frac{0}{3}$ orderly, also a long term resident in the leprosy ward, commented that when the patient arrived at Goroka $\frac{5}{2}$ Base Hospital in 1975 he noticed then that he had $>$ developed grimacing and involuntary movements.

The clinical features of HD in this family appear $N_{0}$ to be quite typical. The mean onset of clinical disease in the two dead patients was 40.5 years, compared with $35 \cdot 5$ to $43 \cdot 2$ years reported in large $\underset{\omega}{N}$ series. ${ }^{511}$ In New Britain the mean onset of disease was 28 years $^{2}$ and in Papua it was 30 years. ${ }^{3}$ The mean duration of illness in this study was estimated to have $\mathbb{\Phi}$ been 7.5 years, which is relatively short compared $\stackrel{\oplus}{+}$ with the $10 \cdot 5$ to 16 years in most surveys, ${ }^{56}$ and the $\frac{T}{T}$ mean age at death was estimated to have been $47.5 \frac{\text { के }}{\mathbb{D}}$ 
years. The mean age at death in large series is 55 years. ${ }^{12}$ In New Britain, the mean duration of clinical illness was estimated to have been 12.5 years and the mean age at death 42.5 years. ${ }^{2}$ In the Papuan study the data available were insufficient to permit estimation of these factors.

The occurrence of HD in this isolated region of the Eastern Highlands suggests at first the possibility of mutation. However, studies elsewhere have suggested that mutation is very rare in $\mathrm{HD}^{13}$ and evidence for genetic drift should be sought. ${ }^{14}$

Until the late 1940s when first contact was made with Europeans, the Yagaria linguistic group lived in relative isolation in remote Highland valleys and the only outside contact seems to have been the trade links with the Gimi speaking people to the south. ${ }^{15}$ From this direction, trade items including pottery were imported from the Gulf of Papua. ${ }^{16}$ One of the principal potteries on the Gulf was located on Yule Island (fig 1) close to the Papuan HD focus. ${ }^{3}$ If trade items found their way to the interior, it may be surmised that anomalous genes may have been introduced along the same route.

Accordingly it is conceivable that HD in the Eastern Highlands may have had its source in the Papuan HD focus. In the study of the latter focus it was suggested that HD might have been introduced by foreign seafarers visiting the Gulf of Papua in pre-colonial times, ${ }^{3}$ and these included New England whalemen who were known to have hunted sperm whales in the adjacent Torres Strait whaling grounds. ${ }^{17}$

\section{References}

1 Hetherington HB, Wechszler Z. Huntington's chorea in a native Melanesian family of the British Solomon Islands. Med J Aust 1942;1:599-600.

2 Scrimgeour EM. Huntington's disease in two New Britain families. J Med Genet 1980;17:197-202.
${ }^{3}$ Scrimgeour EM. Huntington's chorea in Papua. Papua New Guinea Med J 1982;25:12-5.

4 Alpers MP. Kuru: age and duration studies. Mimeograph, Department of Medicine, University of Adelaide, 1964.

5 Cameron D, Venters GA. Some problems in Huntington's chorea. Scott Med J 1967;12:152-6.

6 Reed TE, Chandler JH. Huntington's chorea in Michigan. 1. Demography and genetics. Am J Hum Genet 1958;10: 201-25.

7 Prusiner SB, Gajdusek DC, Alpers MP. Kuru with incubation periods exceeding two decades. Ann Neurol 1982;12:1-9.

8 Scrimgeour EM, Masters CL, Alpers MP, Kaven J, Gajdusek DC. A clinico-pathological study of a case of kuru. J Neurol Sci (in press).

9 Caine ED, Hunt RD, Weingartner H, Ebert MH. Huntington's dementia: clinical and neuropsychological features. Arch Gen Psychiatry 1978 ;35:377-84.

10 Hornabrook RW. Kuru. In: Hornabrook RW, ed. Topics on tropical neurology. Philadelphia: Davis, 1975: 71-90.

11 Bell J. Huntington's chorea. In: The treasury of human inheritance. Vol 4, part 1. London: Cambridge University Press, 1934.

12 Heathfield KWG. Huntington's chorea: a centenary review. Postgrad Med J 1973;49:32-45.

13 Reed TE, Neal JV. Huntington's chorea in Michigan. Am J Hum Genet 1959;17:107-36.

14 Bruyn GW. Huntington's chorea: historical, clinical and laboratory synopsis. In: Vinken PJ, Bruyn GW, eds. Handbook of clinical neurology. Amsterdam: NorthHolland, 1968:298-378.

15 Rench GL. Yagaria dictionary. Canberra: Australian National University, 1977.

16 Hughes IM. Stone age trade in the New Guinea inland: historical geography without history. In: Brookfield HC, ed. The Pacific in transition: geographical perspectives on adaption and change. Canberra: Australian National University Press, 1973: 97-126.

17 Scrimgeour EM. Possible introduction of Huntington's chorea into Pacific islands by New England whalemen. Am J Med Genet (in press).

Correspondence and requests for reprints to Dr E M Scrimgeour, 51 Woodroyd Street, Mount Lawley, Western Australia 6050. 